\title{
Using Bayesian Aldrich-McKelvey Scaling to Study Citizens' Ideological Preferences and Perceptions
}

\author{
Christopher Hare \\ Department of Political Science, University of Georgia \\ 104 Baldwin Hall \\ Athens, GA 30602 \\ chare@uga.edu \\ David A. Armstrong II
}

Department of Politics, University of Wisconsin - Milwaukee

PO Box 413

Milwaukee, WI 53211

armstrod@uwm. edu

Ryan Bakker

Department of Political Science, University of Georgia

104 Baldwin Hall

Athens, GA 30602

rbakker@uga.edu

Royce Carroll

Department of Political Science, Rice University

P.O. Box 1892 MS-24

Houston, TX 77251

rcarroll@rice.edu

Keith T. Poole

Department of Political Science, University of Georgia

104 Baldwin Hall

Athens, GA 30602

ktpoole@uga.edu

July 2, 2014 


\section{Running Head: "Bayesian Aldrich-McKelvey Scaling"}

Keywords: ideology, measurement, Bayesian methods, polarization, ideal point estimation

Abstract: Aldrich-McKelvey scaling is a powerful method that corrects for differentialitem functioning (DIF) in estimating the positions of political stimuli (e.g., parties and candidates) and survey respondents along a latent policy dimension from issue scale data. DIF arises when respondents interpret issue scales (like the standard liberal-conservative scale) differently and distort their placements of the stimuli and themselves. We develop a Bayesian implementation of the classical maximum likelihood Aldrich-McKelvey scaling method that overcomes some important shortcomings in the classical procedure. We then apply this method to study citizens' ideological preferences and perceptions using data from the 20042012 American National Election Studies and the 2010 Cooperative Congressional Election Study. Our findings indicate that DIF biases self-placements on the liberal-conservative scale in a way that understates the extent of polarization in the contemporary American electorate and that citizens have remarkably accurate perceptions of the ideological positions of Senators and Senate candidates.

Acknowledgements: An earlier version of this paper was presented at the 2014 Annual Meeting of the Southern Political Science Association. We thank Jidong Chen for his valuable feedback. We would also like to thank the editor and the anonymous reviewers who offered helpful comments and suggestions during the review process. Data for replication, R code, and BUGS/JAGS scripts are available at: http://www.voteview.com/BAM.asp. All replication materials are also available on the AJPS Data Archive on Dataverse (http: //dvn.iq.harvard.edu/dvn/dv/ajps). 


\section{Introduction}

It is difficult to overstate the extent to which our knowledge of the political world has benefitted from survey research. Surveys like the American National Election Studies have made it possible for countless scholars to investigate questions of vital importance to the functioning of our democratic society. For example, do citizens possess spatial awarenessthat is, an understanding of their position relative to other political figures on important dimensions of political competition? If citizens do possess this spatial awareness, then at the individual level, citizens can use this information to make informed decisions about their own political futures including holding current officeholders accountable for perceived policy-oriented transgressions. Further, individual preferences can provide a sense of the distribution of preferences in the aggregate. Reliable information of this sort is required to assess the extent and character of popular representation. One of the most salient questions in contemporary American politics concerns the extent to which the mass public can be characterized as ideologically polarized. Notably, Fiorina, Abrams and Pope (2011) have used survey data to argue that the American public has remained centrist in the aggregate while their political representatives have become decidedly non-centrist (McCarty, Poole and Rosenthal, 2006).

Unfortunately, survey responses can obscure, rather than illuminate, the true nature of the political world. Both Brady (1985) and King et al. (2004) have identified a problem with issue scales (the main source of data for answering these types of questions) called differential item-functioning (DIF). DIF (or interpersonal incomparability) arises when respondents interpret and answer survey items such as issue scales differently. Two respondents with the same opinion may nonetheless place themselves at different positions on the scale, or two respondents with different opinions may locate themselves at the same position. While this problem may seem to be largely methodological in nature, we show below that it has some important substantive implications. In particular, we might expect that many respondents place both themselves and their preferred candidate/party in the middle of the scale while 
pushing stimuli they dislike toward the extremes. For instance, a conservative respondent may place the Democratic Party on the far left edge of the scale, while a liberal respondent will be more likely to perceive the Democratic Party and herself as centrist. This would have the effect of making the electorate artificially appear less polarized. DIF of this form also limits comparability between respondents across ideologically disparate electoral or geographic units like states and hinders our ability to evaluate the accuracy of citizens' ideological perceptions of their representatives.

Aldrich and McKelvey's (1977) pathbreaking solution to the problem of DIF is to treat raw placements as linear distortions of the "true" positions of the stimuli (e.g., political parties and candidates). By estimating each respondent's perceptual distortion parameters (the intercept/"shift" and weight/"stretch" terms), it is possible to recover the underlying locations of the stimuli as well as the respondents (if self-placement questions are included in the survey) on a common latent dimension from issue scale data. The Aldrich-McKelvey (A-M) method was one of the first statistical scaling procedures based upon the spatial (geometric) theory of choice and judgment. Nearly forty years after its development, political scientists continue to employ A-M scaling to study a variety of political contexts (e.g., Saiegh, 2009; Hollibaugh, Rothenberg and Rulison, 2013; Lo, Proksch and Gschwend, 2014). Gary King and Jonathan Wand have also introduced a DIF-correction method based on anchoring vignettes that is equivalent to a nonparametric version of the A-M model (King and Wand, 2007; Wand, 2013) .

However, A-M scaling has been an underutilized tool in general the estimation of spatial models of public opinion and in particular to answer the important questions posed above. In part, oversight of the A-M scaling method can be attributed to the technical complexities of actually running the classical maximum likelihood (ML) A-M procedure, which was originally written in FORTRAN code and has only recently been made available as an $\mathrm{R}$ function in the

\footnotetext{
1 "Anchoring vignettes" are stimuli that are familiar to all of the respondents. These can be real (e.g., the Republican Party or President Obama) or fictional. For example, Bakker, Jolly, Polk and Poole (2014) ask expert informants to place fictional parties with hypothetical platforms on a left-right scale, and use these placements to bridge across European countries.
} 
basicspace package (Poole et al., 2013). There are also some important limitations to classical A-M scaling. First, it does not allow for the inclusion of individuals with missing responses. This becomes problematic not only because of high rates of missing data in public opinion surveys, but also when it becomes necessary to "bridge" across data from different respondent groups (e.g., nations or congressional districts) and/or time periods since missing data will necessarily be present. Second, uncertainty bounds for the stimuli positions are not directly estimated but can be approximated via bootstrapping. More importantly, though, there is no satisfactory way to estimate uncertainty in the individual distortion parameters and, hence, in the respondent ideal points using classical A-M scaling.

In this paper, we address these deficiencies by developing a Bayesian implementation of the A-M scaling mod el. In this setup, missing data are easily accommodated and Markov chain Monte Carlo (MCMC) methods produce more realistic measures of uncertainty (i.e., 95\% credible intervals) for both the stimuli and the distortion parameters. These measures facilitate the appropriate use of A-M results in outside models by allowing the researcher to incorporate uncertainty inherent in estimates of latent variables. Our adaptation preserves the underlying A-M model while providing a more attractive means of estimation. This innovation allows us to provide more rigorous and appropriate answers to the questions posed above and will hopefully allow other scholars using issue scale data to do the same.

The paper proceeds as follows. We first elaborate on the problem of DIF, how it systematically biases survey responses, and how the A-M model solves this problem. We then develop a version of this model that is akin to a re-indexed Bayesian factor model (see Quinn, 2004 and Jackman, 2009) that can be estimated using standard MCMC methods. The subsequent sections apply the method to two important questions in the study of American politics. First, we present evidence that respondents bias their liberal-conservative ideological scale placements such that they place themselves and their preferred candidate(s) near the middle while pushing opposing candidates to the extremes. In Sections 4 and 5, we demonstrate that this bias has important substantive implications for the study of citi- 
zens' ideological preferences and perceptions. First, we show that DIF understates the true extent of polarization in liberal-conservative self-placement data. Second, we employ the Bayesian A-M method to address the problem of comparability in respondent perceptions across states. Correcting for DIF allows us to make valid cross-state comparisons of respondents' ideological perceptions of Senators and Senatorial candidates and assess how they compare with alternative measures based on roll call votes and campaign contributions $2^{2}$ Section 6 concludes with an assessment of how Bayesian A-M scaling can contribute to the field of ideal point estimation and scaling methodology.

\section{Differential Item Functioning in Survey Responses and the Aldrich-McKelvey Solution}

Placing oneself and political stimuli like parties or candidates on an issue scale is a task of perception, and there are many ways in which survey respondents' perceptions can be systematically distorted. First, ideological centrists and extremists view the political world differently, even if they agree on the ordering of stimuli on a policy dimension. Extremists have more intense, sharply peaked utility functions and perceive greater distance between themselves and the alternatives (Sherif and Hovland, 1961; Carroll et al., 2013). Consequently, ideological extremists who view all parties or candidates as insufficiently liberal or conservative should be inclined to push the stimuli toward one end of the scale. Consider, for example, a far left activist and and a far right activist. Both might agree that President Obama is to the left of Mitt Romney. But the far left activist may perceive Romney to be on the far-right and Obama to be moderate or even slightly conservative. Conversely, the far right activist is likely to view Obama as extremely liberal and Romney as a centrist.

Second, because the term "moderate" has a positive connotation in politics (i.e., it implies

\footnotetext{
${ }^{2}$ Recent work by Jacoby and Armstrong (2014) indicates that citizens can and do use ideology to evaluate national candidates and elected officials, and Bayesian A-M scaling allows us to assess this claim at the state level.
} 
being reasonable, sensible, objective, etc.), we expect that respondents will be more likely to use that term or position to describe themselves and their preferred candidate and party, even if those stimuli are decidedly non-centrist. There has been a considerable amount of work that has examined why Americans favor the "conservative" over the "liberal" label (e.g., Free and Cantril, 1967; Ellis and Stimson, 2012), but less attention has been paid to whether social desirability bias leads to overuse of the middle position of issue scales. We hypothesize that many respondents place themselves and their preferred candidate/party near the middle of the scale while pushing the opposing candidate/party closer to either of the ends of the scale.

Finally, respondents also distort their issue scale placements by reversing the ordering of stimuli. This would include, for instance, placing the Republican Party to the left of the Democratic Party. This behavior is concentrated among those with low levels of political sophistication (Palfrey and Poole, 1987), although its frequency (both on the liberalconservative scale and several specific issue scales) has declined over recent decades (Levendusky, 2009).

Aldrich and McKelvey (1977) develop a scaling method that diagnoses and corrects for these types of distortions by modeling respondents' placements as a linear function of the true location of the stimuli and two individual-specific transformation parameters. The first parameter (the $\alpha$ or intercept term) allows for shifts in the reported placements to the left or right. The second parameter (the $\beta$ or weight term) expands or contracts the reported placements on the scale, reversing them when $\beta$ is negative. Hence, respondents with negative weight terms (i.e., $\left.\beta_{i}<0\right)$ possess lower levels of political information than respondents with positive weights..$^{3}$

The A-M model is presented in equation (1). Let $z_{i j}$ be the reported placement of stimulus

\footnotetext{
${ }^{3}$ We provide the results of several tests in support of this claim in the Supporting Information/
} 
$j(j=1, \ldots, q)$ by individual $i(i=1, \ldots, n)$ :

$$
z_{i j}=\alpha_{i}+\beta_{i} \zeta_{j}+u_{i j}
$$

where $\zeta_{j}$ is the true position of stimuli $j, \alpha_{i}$ is the intercept/"shift" term, $\beta_{i}$ is the weight or "stretch" term, and $u_{i j}$ satisfies the usual Gauss-Markov assumptions of zero mean, homoscedasticity, and independence (Aldrich and McKelvey, 1977, p. 113).

As noted above, the A-M model has traditionally been estimated in a maximum likelihood (ML) framework, which has two important deficiencies. First, it does not estimate uncertainty in the point estimates. Though a bootstrapping scheme can be used to develop uncertainty bounds for the stimuli estimates, it remains infeasible to calculate uncertainty estimates for the individual distortion parameters. As we show in the next section, this precludes the estimation of uncertainty bounds for the respondent ideal points. Second, the ML method does not allow for the inclusion of respondents with missing values. Not only does this waste a lot of usable data (e.g., a respondent who places all but one of the stimuli), but it also prevents the use of "bridged" issue scale data in which respondents are asked to place only some of the stimuli. For instance, respondents in different states or congressional districts may be asked to place their representatives as well as some common stimuli (e.g., the Democratic Party) on an issue scale. Theoretically, the common stimuli can be used to bridge across regions or time to place all of the stimuli on a common scale, and this has been implemented in other applications (Poole, 2005; Shor and McCarty, 2011; Bakker, Jolly, Polk and Poole, 2014). However, because respondents are not asked to place all of the stimuli, missing values will be present for every respondent and the existing method cannot accommodate this data structure. These issues motivate our development of a Bayesian method of estimating the A-M scaling model. 


\subsection{The Bayesian Aldrich-McKelvey Scaling Model}

Rather than employ a loss function to develop a Bayesian implementation of the A-M model, we instead estimate a variation of a Bayesian factor model (e.g., Quinn, 2004, Jackman, 2009, chap. 9). In the standard factor model set-up, the latent variable or factor is indexed by individual whereas the factor loadings are held constant across all observations. The A-M procedure, however, reverses this indexing. That is, the factor loadings are allowed to vary across individuals whereas the latent variable is held constant. This follows directly from the discussion above in that the true positions of the stimuli are the same for all respondents whereas the parameters that map the respondents' perceived placements of the stimuli to the true placements are specific to the individual.

While Aldrich and McKelvey (1977) solve for $\zeta_{j}$ first and subsequently calculate the individual transformation parameters $\alpha_{i}$ and $\beta_{i}$, in the Bayesian framework we can estimate both quantities simultaneously. As Jackman (2000) describes, in Bayesian estimation all unknown quantities are treated in the same manner. Once the model is specified, we sample from the joint posterior distribution of all unknown parameters, whether they are missing data values, regression parameters, latent variable scores, or any other unknown. In our model, we sample from the joint posterior for the individual transformation parameters and the true stimuli positions. Identification of this model is achieved through the priors on the unknown parameters. ${ }^{4}$ Given that we sample directly from the posterior distribution of the unknowns, it is trivial to compute standard errors for these estimates.

The Bayesian A-M model assumes that the $z_{i j}$ (the perceived location of stimulus $j$ by individual $i$ ) are distributed in the following manner:

\footnotetext{
${ }^{4}$ For a more complete discussion on identification and estimation of Bayesian latent variable models, see Jackman 2000, 2001.
} 


$$
\begin{aligned}
& z_{i j} \sim N\left(\mu_{i j}, \tau_{i j}\right) \\
& \mu_{i j}=\alpha_{i}+\beta_{i} \zeta_{j} \\
& \tau_{i j}=\tau_{i} \tau_{j}
\end{aligned}
$$

We employ non-informative uniform priors for the individual transformation parameters $\alpha_{i}$ and $\beta_{i}$ :

$$
\begin{aligned}
\alpha_{i} & \sim U(-100,100) \\
\beta_{i} & \sim U(-100,100)
\end{aligned}
$$

Standard normal priors are used for the estimates of the stimuli positions $\left(\zeta_{j}\right)$. The polarity of the scale can be set by constraining a liberal stimulus to lie between -1.1 and -0.9 [i.e., $N(0,1) T(-1.1,-0.9)$ ] and a conservative stimulus to lie between 0.9 and 1.1. This is adapted from the standard $-1 /+1$ constraint that is sufficient for identification Clinton, Jackman and Rivers, 2004), but also allows for uncertainty in the point estimates of these stimuli.

$$
\zeta_{j} \sim N(0,1)
$$

Finally, unique stimuli and respondent error variances are estimated to allow for heteroskedastic error. Diffuse inverse Gamma priors are used for both the stimuli and respondentspecific precision terms $\left(\tau_{j}\right.$ and $\tau_{i}$, respectively). Inverse Gamma hyperpriors are also placed on the shape and scale parameters of the inverse Gamma priors for the $\tau_{i}$ terms. This has the practical effect of introducing exchangeability between the $\tau_{i}$ parameters. 


$$
\begin{aligned}
\tau_{j} & \sim \operatorname{Gamma}(0.1,0.1) \\
\tau_{i} & \sim \operatorname{Gamma}(\nu, \omega) \\
\nu & \sim \operatorname{Gamma}(0.1,0.1) \\
\omega & \sim \operatorname{Gamma}(0.1,0.1)
\end{aligned}
$$

In the examples used in this paper, MCMC estimation of the model is conducted using JAGS (Just Another Gibbs Sampler) and the R package rjags (Plummer, 2003, 2013). We require that respondents provide placements of at least three stimuli to be included in the analysis. In each case, we run two chains, discarding the first 50, 000 iterations as a burnin period and summarizing the results of the remaining 10,000 iterations with a thinning interval of 10. The chains show strong evidence of convergence according to the GelmanRubin diagnostic, the Geweke diagnostic, and the unimodality of the posterior distributions.

Finally, equation (12) uses respondents' self-placements $\left(z_{i(s e l f)}\right)$ and estimated distortion parameters $\left(\alpha_{i}\right.$ and $\left.\beta_{i}\right)$ to calculate their ideal point $\left(x_{i}\right)$ in the same metric as the estimated stimuli positions:

$$
x_{i}=\frac{z_{i(s e l f)}-\alpha_{i}}{\beta_{i}}
$$

In the Bayesian framework, this means that we take successive draws from the posterior densities of $\alpha_{i}$ and $\beta_{i}$ to calculate a distribution for individual $i$ 's ideal point. This allows uncertainty in the estimates of $\alpha_{i}$ and $\beta_{i}$ to flow through to the ideal point estimates, another advantage of the Bayesian A-M procedure. Note in equation 12 that $\lim _{\beta_{i} \rightarrow 0}=\infty$, and so we use the median value as the point estimate of the respondent positions since the median will be more robust to long tails produced when posterior draws of $\beta_{i}$ are very close to 0 . 


\section{Diagnosing Differential Item Functioning in Survey Responses}

Do respondents place themselves and their favored candidate(s) at more moderate positions while pushing opposing candidates(s) toward the extremes? We address this question using data from the 2012 American National Election Study (ANES) and the 2010 Cooperative Congressional Election Study (CCES). To recap, the A-M model treats respondents' place-

ments as a function of the "true" positions of the stimuli and a set of individual-specific linear mapping parameters (that is, $z_{i j}=\alpha_{i}+\beta_{i} \zeta_{j}+u_{i j}$ ). In substantive terms, this means that positive values of $\alpha$ (the intercept or "shift" term) indicate that the respondent places the stimuli (and by extension, herself) too high on the scale, while negative $\alpha$ values indicate the opposite. For example, on the standard liberal-conservative scale in which higher values denote greater conservatism, positive $\alpha$ values indicate that the respondent is over-using the conservative side of the scale (pushing stimuli too far rightward) and negative $\alpha$ values indicate that the respondent is over-using the liberal end of the scale (pushing stimuli too far leftward). We would expect, then, that liberal respondents would have higher and positive $\alpha$ values than conservative respondents, who would have lower and negative $\alpha$ values.

Tables 12 help illustrate the substantive meaning of the $\alpha$ values from A-M scaling. These provide four (two Republicans and two Democrats) 2012 ANES respondents' rawplacements of their party and themselves on the seven-point liberal-conservative scale, the posterior mean of their $\alpha$ term (with $95 \%$ credible interval), and their open-ended answers about what they dislike about their party. All of these respondents criticize their party for being too moderate, a sentiment that should be reflected in their ideological placements and their $\alpha$ term. This is precisely what we see: both Republicans have negative $\alpha$ values (meaning they rate the stimuli as too liberal), while both Democrats have positive $\alpha$ values (meaning they rate the stimuli as too conservative). Presumably, these respondents are also understating the extent of their own liberalism or conservatism. 
We next more systematically consider the relationship between respondents' $\alpha$ values and their ideological and partisan preferences. First, Figure 1 shows the distribution of respondents' mean $\alpha$ values across partisan and ideological groups in the 2012 ANES. As we would expect, the $\alpha$ means of Democrats and self-identified liberals tend to be positive (meaning that they overuse the conservative end of scale) while the $\alpha$ means of Republicans and self-identified conservatives tend to be negative (meaning that they overuse the liberal end of the scale) $4^{5}$ The importance of this result is that, in most cases, liberal Democrats and conservative Republicans are understating their own ideological extremism in their selfplacements.

It is also important to note from Figure 1 that while the $\alpha$ estimates for independents and self-identified moderates are centered at 0 , there is also high variance. That is, there are a considerable number of respondents in both groups with non-negligible positive or negative $\alpha$ means whose own ideological placements need to be shifted to the left or right. These are illusory moderates. They may perceive themselves as moderate, but their ratings of political stimuli calls their self-placements into question. While Treier and Hillygus (2009) have argued that moderate identification can mask underlying cross-pressures between liberal and conservative attitudes on economic and social issues, our findings indicate that it may also hide more extreme positions on a single liberal-conservative dimension.

Of course, Figure 1 is subject to the criticism that we are using a measure (ideological self-placement) that is itself biased by DIF to diagnose DIF. To address this problem, we turn to data from the 2010 CCES to develop an alternative measure of ideological position and examine its relationship to respondents' mean $\alpha$ values ${ }^{6}$ The 2010 CCES asked respondents whether they support or oppose a series of eight policy proposals also voted on by the 111th US Congress.$^{7}$ Because respondents must choose either support or oppose, DIF of the kind

\footnotetext{
${ }^{5}$ The correlation between partisanship and mean $\alpha$ value is -0.37 and between ideological self-placement and mean $\alpha$ value is -0.38 .

${ }^{6}$ To ease the computational burden, we randomly select with replacement 200 respondents from each state.

${ }^{7}$ These include the American Recovery and Reinvestment Act (the 2009 stimulus) [CC332A], the the State Children's Health Insurance Program [CC332B], the American Clean Energy and Security Act [CC332C], the
} 
that we are concerned about is not problematic. We simply use the proportion of non-missing responses that are conservative as our alternative ideological measure.

Table 3 reports the results of separate OLS regressions of respondent mean $\alpha$ values onto ideological self-placements and the measure based on roll call votes using the 2010 CCES data. As in Figure 1 and consistent with the hypothesized relationship, both ideological variables exert a negative effect on the $\alpha$ term. In fact, respondent ideology as measured using their roll call vote preferences has an even stronger relationship with the mean $\alpha$ values than the raw self-placements. This provides strong evidence that respondents' ideological positions systematically influence their issue scale placements, with more liberal respondents pushing stimuli too far rightward and conservative respondents doing just the opposite. Moreover, 34\% of self-identified moderates $(570 / 1663)$ are in the most liberal or most conservative quartiles of the ideological measure constructed from the roll call votes.

\section{Re-Considering the Distribution of Citizens' Ideo- logical Preferences}

We have thus far shown that respondents bias their placements on issue scales in systematic ways that can be diagnosed and corrected for by A-M scaling. This section proceeds with an assessment of how DIF affects survey respondents' self-placements on the standard liberalconservative scale and our use of this data to analyze the distribution of mass ideological preferences. In particular, this data has obvious relevance to the study of polarization in the contemporary American electorate and is frequently used to examine whether citizens have followed elites and become more extreme in their own policy preferences. A quick review of this data suggests not: since 1972, the modal response to the American National Election

Comprehensive Health Reform Act (the Affordable Care Act) [CC332D], the appointment of Elena Kagan to the US Supreme Court [CC332E], the Dodd-Frank financial reform bill [CC332F], repealing Don't Ask, Don't Tell [CC332G], and federal funding of embryonic stem cell research [CC332I]. Cronbach's $\alpha$ for these eight items is 0.91 (the Kuder-Richardson coefficient of reliability [KR-20], an analogue of Cronbach's $\alpha$ for dichotomous responses, is also 0.91$)$. 
Studies (ANES) liberal-conservative scale has been the moderate category, with only a small percentage of respondents rating themselves as "extreme liberals" or "extreme conservatives" (ANES, 2010). The same pattern holds up with most other scales concerning specific policy issues like government spending or abortion.

Some, most notably Fiorina, Abrams and Pope (2011), have used this data to argue that the American public has remained centrist in the face of intense elite polarization (see also Fiorina and Abrams, 2008, 2012 and DiMaggio, Evans and Bryson, 1996). Others have pointed out that the distribution of respondents becomes more bimodal when isolating actual voters or politically informed/engaged citizens (e.g., Palfrey and Poole, 1987; Abramowitz and Saunders, 2008; Abramowitz, 2010; Lauderdale, 2013). These types of respondents have more polarized preferences as well as greater influence in the political arena. For the public as a whole, though, self-placements on most of these issue scales-particularly the liberal-conservative scale - follow an approximate bell curve pattern, and this has important implications for measuring polarization in the mass public. Hetherington and Weiler (2009, p. 19), for example, write that:

Fiorina quite convincingly shows that Americans' issue preferences have been and remain generally moderate (see also Evans 2003). A key piece of his evidence is the National Election Study's (NES) ideological self-placement question. When people are asked to place themselves on a 7-point scale from extremely liberal at one end to extremely conservative at the other with moderate, middle of the road at the midpoint, about 50 percent of Americans either characterize themselves as moderate or are unable to place themselves on the scale.

What is left out of this discussion, however, is an analysis of how DIF biases respondents' self-placements on the liberal-conservative scale. Our findings in the previous section clearly lead to the hypothesis that DIF should understate the true level of ideological polarization in the electorate. Ideologues and partisans tend to push stimuli (including themselves) too far to the opposite end of the scale, and many self-identified moderates are not true centrists. These patterns stand out the 2012 ANES data. For instance, of the respondents who voted 
for Obama and provided placements of themselves and Obama on the liberal-conservative scale, 31\% (663 / 2166) rated both themselves and Obama as "moderate" or "slightly liberal." Among Romney voters, 21\% (388 / 1622) rated themselves and Romney as "moderate" or "slightly conservative." The placements of respondents the former group should be moved to left, while the placements of those in the second group should be moved rightward. The same is also true of the $60 \%(997 / 1656)$ of Romney voters who placed Obama at the leftmost position ("extremely liberal") and the $32 \%$ of Obama voters who placed Romney at the rightmost position ("extremely conservative").

Once we correct for DIF in respondents' placements, what does the ideological distribution of the American electorate look like? Figure 2 compares the raw and Bayesian A-M estimates of the liberal-conservative self-placement data in the 2012 ANES. The left panel shows the distribution of respondents' self-placements on the liberal-conservative scale. These data paint a clear picture of a centrist electorate: the distribution follows a bell curve pattern with a marked peak in the middle and with only a small proportion of respondents at either extreme.

However, the Bayesian A-M ideal point estimates — shown in the right panel of Figure 2 tell a more nuanced story about the ideological makeup of the contemporary American electorate. The dark gray bins isolate respondents with positive mean $\beta$ (the weight term) values, meaning that they correctly placed liberal stimuli to the left of conservative stimuli. As discussed in the previous section, we use the positive weight threshold to filter respondents who meet a baseline level of political information

Both distributions of Bayesian A-M ideal point estimates - all respondents and only those with positive weights - exhibit greater polarization than the raw self-placement data. The peaks of the distributions are far flatter and extend outward to the major party presidential candidate point estimates (shown with the "O" and "R" labels at the bottom). Indeed, a little less than half $(44 \%)$ of respondents have estimated ideal points more extreme than Obama or Romney. We might more accurately characterize these distributions are trimodal, 
with peaks at the center and around each of the estimated candidate positions (e.g., Downey and Huffman, 2001). Of course, we should be cautious since there is uncertainty in the these point estimates, but at the very least these results shed doubt on the common practice of using raw self-placement data to measure polarization. The ideological center appears to hollow out once we account for DIF.

Indeed, the ideological distribution of respondents with positive weights clearly shows the greatest amount of polarization, with many moderates disappearing once we remove those who confuse the liberal and conservative labels as applied to the parties and presidential candidates. This result is very much in line with the findings of Palfrey and Poole (1987) and Abramowitz (2010): as we focus on more informed and engaged segments of the electorate, we find higher levels of ideological polarization. These are the citizens with the loudest voice in American politics, and Bayesian A-M scaling reveals the extent of their polarization.

As a final test, we adopt Levendusky and Pope's (2011) approach of measuring polarization with the overlap coefficient. The overlap coefficient measures the overlap or shared area between two distributions; for example, between Republicans and Democrats on an ideological dimension. Given two probability densities $f$ and $g$, the overlap coefficient is defined as

$$
\Delta(f, g)=\int \min \{f(x), g(x)\} d x
$$

and ranges between 0 (no overlap) to 1 (complete overlap), so that lower values indicate higher attitudinal polarization.

We estimate the overlap coefficient using the nonparametric estimator $\left(\hat{\Delta}_{4}\right)^{8}$ in Equation 14 from Schmid and Schmidt (2006) and implemented in the R package overlap (Mered-

${ }^{8}$ Ridout and Linkie $\mid(2009)$ recommend use of this estimator when sample sizes are larger than 75. 
ith and Ridout, 2013):

$$
\hat{\Delta}_{4}=\frac{1}{2}\left(\frac{1}{n} \sum_{i=1}^{n} \min \left\{1, \frac{\hat{g}\left(x_{i}\right)}{\hat{f}\left(x_{i}\right)}\right\}+\frac{1}{m} \sum_{i=1}^{m} \min \left\{1, \frac{\hat{f}\left(y_{i}\right)}{\hat{g}\left(y_{i}\right)}\right\}\right)
$$

Our goal is to compare the overlap between voters supporting each of the two major party presidential candidates in 2004, 2008, and 2012 based on each of the two measures of liberal-conservative position: the raw self-placement data and the DIF-corrected Bayesian A-M ideal point estimates. We use a bootstrapping approach to estimate $95 \%$ confidence intervals for the overlap point estimates for the raw liberal-conservative self-placements, sampling with replacement over 1,000 trials and then calculating the standard deviations of the series of point estimates. We aggregate uncertainty in the Bayesian A-M ideal points to develop $95 \%$ credible intervals for the overlap coefficients from these estimates. A random draw is taken from the posterior distribution of each respondent's ideal point, an overlap score is computed for these draws, and the process is repeated 1,000 times 9 This gives us a distribution of overlap coefficients, for which we calculate the $95 \%$ credible interval. The results are summarized in Figure 3 .

Across all years, the overlap between party identifiers (with leaners) and voters of the Democratic/Republican presidential candidates is greater according to raw liberal-conservative self-placements than the Bayesian A-M ideal point estimates. That is, after accounting for DIF using Bayesian A-M scaling, voters are more polarized (less overlap) than when using raw self-placement data. In all cases, the difference in overlap coefficients between the raw self-placements and the Bayesian A-M estimates is statistically significant at conventional levels. The differences between the two sets of overlap coefficients are also substantively large, in no case less than 0.09 (or about an $18 \%$ decrease in overlap from the raw self-placement data to the Bayesian A-M ideal point estimates). It is also noteworthy that the overlap point estimates show the most pronounced drop in 2012 - the most recent year studied.

\footnotetext{
${ }^{9}$ Extreme draws that are greater or less than 10/-10 are excluded from the analysis.
} 


\section{Citizens' Ideological Perceptions of Legislators and Candidates}

How well do voters judge the ideological positions of legislators and candidates? This question has obvious relevance for assessing the quality of democratic representation, as the roll call vote choices of both federal and state legislators are primarily driven by their positions on the liberal-conservative dimension (Poole and Rosenthal, 2007; Shor and McCarty, 2011). Hence, the vast majority of policy outcomes in Congress and state legislatures can be explained by the distribution of their members along the ideological spectrum. In order for voters to hold representatives maximally accountable, then, they must be able to distinguish between political actors on an ideological metric.

A number of classic works - namely, Miller and Stokes (1963) and Converse (1964) - have established a pessimistic outlook on this question. According to this literature, most citizens do not think ideologically and are ignorant of their representatives' policy positions, even on salient issues. Coupled with more recent findings that low levels of political information continue to be widespread in the American electorate (e.g., Delli Carpini and Keeter, 1996), we might conclude that ideological nuance is beyond the reach of most citizens.

However, a more recent stream of research has a more optimistic take on citizens' ability to gauge the ideological positions of legislators and candidates. First, survey research shows that citizens have a better grasp of their representatives' roll call vote behavior than commonly assumed (Ansolabehere and Jones, 2010), especially on salient roll call votes (Nyhan et al., 2012). Second, moderate congressional candidates outperform extreme ones at the ballot box, ceteris paribus (Ansolabehere, Snyder and Stewart, 2001; Bonica, 2014). Political polarization has also brought ideology to the forefront of American politics, making ideological terms and labels more accessible and producing greater recognition of policy differences between the Democratic and Republican parties (Levendusky, 2009; Jacoby, 1995). Certainly, the fact that so many issues now collapse onto a single liberal-conservative dimen- 
sion (Layman and Carsey, 2002) facilitates use of this dimension in the mass public. For instance, a voter who knows a candidate holds an extreme position on a visible, "easy" issue like abortion can reasonably infer that legislator holds strong liberal or conservative stances on a host of other issues. This was not the case as recently as twenty years ago (Poole and Rosenthal, 1997).

Finally, studies of campaign effects have shown that voters become better informed about candidates' policy stances over the course of political campaigns (Franklin, 1991; Alvarez, 1997) —including statewide party primaries (Hirano et al., 2014) — and in competitive political environments (Jones, 2013). Voters seem to balance dual information flows from positive and negative/attack advertising in campaigns to develop more precise inferences about the candidates' policy stances (Geer and Vavreck, 2014). Most importantly though, Jacoby and Armstrong (2014) find that citizens use information about the ideological positions of political actors to make affective evaluations (i.e., using feeling thermometers) about them. Given these results, we hypothesize that respondents will be able to ideologically differentiate between Senators and Senatorial candidates of the same party and, especially, of different parties.

We test this hypothesis using survey data from the 2010 Cooperative Congressional Election Study (CCES). The 2010 CCES respondents were asked to place themselves, four national stimuli (President Obama, the Democratic and Republican parties, and the Tea Party) on a seven-point liberal-conservative scale. As in Section 3, we randomly select with replacement 200 respondents from each state. We analyze this data using Bayesian A-M scaling, using the four national stimuli to "bridge" across the states. This type of data cannot be analyzed using classical (ML) A-M scaling since respondents with missing data are excluded from the analysis and every respondent will necessarily have missing placements (e.g., a California respondent cannot rate a Senate candidate in New Hampshire) in this setup.

The Bayesian A-M estimates of the stimuli locations across states are directly comparable, correcting for DIF at both the individual and statewide level. At with respondents, we expect 
liberal states to have higher $\alpha$ values (overstating the conservatism of stimuli) than more conservative states. Figure 4 compares the mean placement of Obama on the seven-point liberal-conservative scale with the mean of respondents' $\alpha$ estimates across states. The state mean $\alpha$ values range between -0.45 (South Dakota) and 0.31 (Vermont) and are highly correlated with the state mean Obama placements $(r=0.91)$. The state $\alpha$ means also correlate well with other measures of state ideology such as Obama 2008 vote percentage $(r=0.73)$, with differences attributable to sampling variability. Of course, whether a state oversamples liberal or conservative respondents is irrelevant to Bayesian A-M scaling, which simply calculates and corrects for bias of either type. Generally, though, it is clear from Figure 4 that liberal states like California, Hawaii, and Maryland are placing stimuli too far to the right while states like Louisiana, South Dakota, and Oklahoma are placing stimuli too far to the left. This has obvious implications if we wish to make meaningful cross-state comparisons of citizens' ideological perceptions of political figures.

To assess the validity of the ideological estimates of political stimuli based on survey respondent placements - the BAM scores - we compare them to two external measures of ideology based on roll call voting behavior (Common Space DW-NOMINATE Scores (Poole and Rosenthal, 2007)) and campaign contributions (CF Scores (Bonica, 2014)) ${ }^{10}$ The comparison of aggregated ideological placements with legislators' roll call voting records, in particular, is a crucial test of the vitality of the electoral connection. As Ansolabehere and Jones (2010) [p. 587] explain, "Very high levels of information at the individual level are not necessary for representation to work. One need only require that the average perceptions of constituencies square with the voting records of Representatives. The law of large numbers would make the electorate as a whole act as if individuals were highly informed (Erikson, MacKuen and Stimson, 2002)."

We limit our analysis to all incumbent Senators and the party nominees in 17 competitive

\footnotetext{
${ }^{10}$ We provide the Bayesian A-M point estimates and $95 \%$ credible intervals for the political stimuli in the Supporting Information.
} 
Senatorial races in 2010.11 We exclude non-incumbent Senate candidates in uncompetitive races because voters have little basis to evaluate the ideological positions of "sacrificial lamb" candidates.

Figure 5 illustrates and reports the correlations between BAM scores, both of these measures, and the mean of the raw placements. Because respondents clearly perceive ideological polarization between Democratic and Republican stimuli, the BAM scores and the DW-NOMINATE/CF scores are highly correlated with each other across all stimuli. A more demanding test involves citizens' recognition of ideological differences between stimuli of the same party. Figure 5 also reports the correlations between each set of measures among only Democratic (in blue) or Republican (in red) Senators and Senatorial candidates. These intra-party correlations remain high, especially between BAM and DW-NOMINATE scores $(r=0.75$ for Democrats and $r=0.69$ for Republicans). The intra-party correlations between BAM and CF scores are lower, but are roughly equivalent to the comparable correlations between DW-NOMINATE and CF scores - two well-regarded measures of legislator and candidate ideology.

These results are quite good, given that the BAM estimates are produced exclusively from ordinary citizens' ideological assessments. Of course, voters can only hold candidates accountable for being "out of step" Ansolabehere, Snyder and Stewart, 2001; Canes-Wrone, Brady and Cogan, 2002; Carson et al., 2010) if they recognize the relative ideological positions of political stimuli. While a long line of literature stemming from Miller and Stokes (1963) has demonstrated that citizens are largely unknowledgeable about the issue positions of political elites, they also appear to be able to piece together enough information to approximate the positions of legislators and candidates in ideological space (Hinich and Pollard, 1981; Hinich and Munger, 1994). With a single liberal-conservative dimension structuring the behavior of elite actors in contemporary American politics, democratic accountability requires the

\footnotetext{
${ }^{11}$ We include races in the following states that the Cook Political Report listed as "leaning" or "toss-up" in its 1 November 2010 ratings (The Cook Political Report, 2010): Arkansas, California, Colorado, Connecticut, Florida, Illinois, Indiana, Kentucky, Louisiana, Missouri, Nevada, New Hampshire, Ohio, Pennsylvania, Washington, West Virginia, and Wisconsin.
} 
electorate to operate in this space. Our results provide an optimistic assessment of their ability to do so.

Finally, we compare the BAM scores and the mean placements in order to assess the influence of DIF on the aggregate state estimates. The two sets of scores are highly similar, but there are some differences in the intra-party correlations. More importantly, though, the correlation between the BAM scores and DW-NOMINATE scores (overall and among Democratic stimuli) is higher than the correlation between the mean placements and the DW-NOMINATE scores. Though mean placements provide a close approximation to the BAM scores, correcting for DIF provides us with a more optimistic assessment of citizens' abilities to judge the ideological positions of political stimuli.

It would be reasonable to expect that citizens develop ideological profiles of political stimuli based on both their roll call votes and other factors that also influence donors to contribute to them. As Bonica (2014) explains, "[c]ontributors are free to consider the many ways in which candidates express their ideology beyond how they vote, such as public speaking records, stated policy goals, endorsements, the issues they champion, authored and cosponsored legislation, or cultural and religious values." To test the relative influence of both sets of factors on citizens' ideological perceptions of political stimuli, we regress the BAM scores of Senators and Senatorial candidates with Congressional voting records onto DW-NOMINATE Common Space and CF scores. The OLS results are reported in Table 4 . with additional models isolating Democratic and Republican stimuli. The results indicate that DW-NOMINATE scores exert a larger and consistently significant effect than the CF scores on citizens' ideological perceptions of the selected political stimuli, both overall and within each of the parties. Of course, even though DW-NOMINATE scores are based solely on roll call votes, we should be cautious about attributing the effect of DW-NOMINATE scores on the BAM estimates to roll call voting specifically. Citizens may be able to use general position-taking behavior (Mayhew, 1974) to arrive at an approximation of a legislator's roll call voting record. Some of this is behavior is captured separately by both 
DW-NOMINATE and CF scores. In addition, a little less than half of the total variance in the BAM scores remains unexplained in the separate Democratic and Republican models and is attributable to some combination of random error and other factors not captured by either external measure of ideology. More work is needed, but the degree to which citizens' perceptions of the ideological positions of legislators correspond to their actual voting history remains striking.

\section{Discussion}

Scholars have long recognized the prevalence of interpersonal incomparability or DIF-a problem that arises when respondents interpret and answer survey items in different waysin public opinion data (Brady, 1985, King et al., 2004; Bakker, Jolly, Polk and Poole, 2014). DIF can have important substantive implications. As we have shown in this paper, this includes biasing our understanding of ideological polarization in the contemporary American electorate or limiting the comparability of respondents' placements of legislators and candidates across states.

The A-M scaling method has been an effective remedy for the problem of DIF, but has been under-utilized in political science. This owes in part to some limitations of the classical (maximum likelihood) method; in particular, the absence of reliable uncertainty measures and the requirement that respondents place all of the stimuli to be included in the scaling. The Bayesian implementation of the A-M scaling model that we have presented in this paper addresses these issues, as missing data is accommodated and measures of uncertainty are easily ascertained and interpreted via the posterior densities of the parameters.

We hope that the development of Bayesian A-M scaling will spark renewed interest in applying the A-M model to analyze public opinion or other types of survey data. As we have detailed, the problem of DIF is especially acute when studying polarization in the mass electorate. Many respondents skew the space leftward or rightward, often placing placing 
themselves and their preferred candidate/party too close to the middle of the scale and/or pushing the opposing candidate/party too far toward the extremes of the scale. Once we account for this phenomenon and estimate corrected ideal points for the respondents, the contemporary American electorate appears to be considerably more ideologically polarized than would be inferred by simply looking at the distribution of raw self-placements on the liberal-conservative scale.

We do not mean to assert that our findings are a silver bullet that the contemporary American electorate is indeed polarized. Any single survey item remains contaminated with measurement error - even after correcting for DIF — and multiple items are preferable when measuring a latent concept like ideology (Ansolabehere, Rodden and Snyder Jr., 2008). Accordingly, future work might adapt Bayesian A-M scaling to develop ideological scores that adjust for DIF across multiple issue scales. However, the liberal-conservative scale, in particular, is an efficient summary measure of citizens' ideological positions: one that is strongly related to a range of political attitudes and behaviors (Lewis-Beck et al., 2008). It seems reasonable to assume that this scale will remain prevalent in public opinion research, but we would do well to recognize its limitations (see also Treier and Hillygus 2009). For instance, liberal-conservative self-placement data is frequently marshalled to support the claim that the American electorate is predominately centrist. Our results indicate that this is largely an artifact of DIF.

Bayesian A-M scaling is also a powerful method for generating estimates of the ideological positions of political stimuli from mass survey responses. Citizens have been shown to be quite adept at placing political figures and groups on ideological and issue scales (Brady and Sniderman, 1985), a proposition supported by our results. Indeed, our results indicate that citizens hold hold perceptions of Senators and Senatorial candidates that are very much in line with their ideological locations as measured by roll call voting or campaign contributions. The implication that political elites and the electorate effectively communicate over a single ideological dimension (Hinich and Munger, 1994; Aldrich and Freeze, 2011) is certainly one 
deserving of future work.

Moreover, this type of perceptual data has never been more widespread. For example, the Cooperative Congressional Election Study has included placement questions for congressional candidates since its inception in 2006. Internationally, surveys such as the European Election Study and the Comparative Study of Electoral System have continued to expand the number of countries in which they conduct interviews and the number of parties and candidates that respondents are asked to evaluate. The Chapel Hill Expert Survey (Bakker et al., 2014) has been innovative in using "anchoring vignettes" - descriptions of fictional parties' platformsto bridge across experts' placements of parties in different countries when common stimuli do not exist. Future work using Bayesian A-M scaling could likely make use of this and other surveys that include a larger number of political figures and parties for respondent to place, with the benefit that the individual distortion parameters (and therefore, the respondent ideal points) are more precisely estimated as additional stimuli are included.

We think other research opportunities abound using estimates of stimuli ideological positions from respondent placements. For example, while the relationship between the Bayesian A-M stimuli estimates and external measures of ideology (the DW-NOMINATE and CF scores) appears to be strong, it is not perfect. Why are some stimuli perceived to be more or less ideologically extreme than is indicated by their legislative record or contributor behavior? Are these the deviations random noise or the result of ideological maneuvering? Are placements more accurate (and polarized) during campaign seasons? The results from Bayesian A-M scaling can be used to address these and other questions critical to democratic accountability. 


\section{References}

Abramowitz, Alan I. 2010. The Disappearing Center: Engaged Citizens, Polarization, and American Democracy. New Haven: Yale University Press.

Abramowitz, Alan I. and Kyle L. Saunders. 2008. "Is Polarization a Myth?" Journal of Politics 70(2):542-555.

Aldrich, John H. and Melanie Freeze. 2011. Political Participation, Polarization, and Public Opinion: Activism and the Merging of Partisan and Ideological Polarization. In Facing the Challenge of Democracy: Explorations in the Analysis of Public Opinion and Political Participation, ed. Paul M. Sniderman and Benjamin Highton. Princeton, NJ: Princeton University Press pp. 185-206.

Aldrich, John H. and Richard D. McKelvey. 1977. "A Method of Scaling with Applications to the 1968 and 1972 Presidential Elections." American Political Science Review 71(1):111130.

Alvarez, R. Michael. 1997. Information and Elections. Ann Arbor: University of Michigan Press.

American National Election Studies. 2010. Time Series Cumulative Data File [dataset]. Stanford University and the University of Michigan [producers and distributors].

URL: http://electionstudies.org

Ansolabehere, Stephen, James M. Snyder, Jr. and Charles Stewart, III. 2001. "Candidate Positioning in U.S. House Elections." American Journal of Political Science 45(1):136-159.

Ansolabehere, Stephen, Jonathan Rodden and James M. Snyder Jr. 2008. "The Strength of Issues: Using Multiple Measures to Gauge Preference Stability, Ideological Constraint, and Issue Voting." American Political Science Review 102(2):215-232.

Ansolabehere, Stephen and Philip Edward Jones. 2010. "Constituents Responses to Congressional Roll-Call Voting." American Journal of Political Science 54(3):583-597.

Bakker, Ryan, Catherine de Vries, Erica Edwards, Liesbet Hooghe, Seth Jolly, Gary Marks, Jonathan Polk, Jan Rovny, Marco Steenbergen and Milada Anna Vachudova. 2014. "Measuring Party Positions in Europe: The Chapel Hill Expert Survey Trend File, 1999-2010." Forthcoming, Party Politics.

Bakker, Ryan, Seth Jolly, Jon Polk and Keith T. Poole. 2014. "The European Common Space: Using Anchoring Vignettes to Scale Party Positions across Europe." Forthcoming, Journal of Politics.

Bonica, Adam. 2014. "Mapping the Ideological Marketplace." American Journal of Political Science 58(2):367-386.

Brady, Henry E. 1985. "The Perils of Survey Research: Inter-Personally Incomparable Responses." Political Methodology 11(3-4):269-291. 
Brady, Henry E. and Paul M. Sniderman. 1985. "Attitude Attribution: A Group Basis for Political Reasoning." American Political Science Review 79(4):1061-1078.

Canes-Wrone, Brandice, David W. Brady and John F. Cogan. 2002. "Out of Step, Out of Office: Electoral Accountability and House Members' Voting." American Political Science Review 96(1):127-140.

Carroll, Royce, Jeffrey B. Lewis, James Lo, Keith T. Poole and Howard Rosenthal. 2013. "The Structure of Utility in Spatial Models of Voting." American Journal of Political Science 57(4):1008-1028.

Carson, Jamie L., Gregory Koger, Matthew J. Lebo and Everett Young. 2010. "The Electoral Costs of Party Loyalty in Congress." American Journal of Political Science 54(3):598-616.

Clinton, Joshua, Simon Jackman and Douglas Rivers. 2004. "The Statistical Analysis of Roll Call Data." American Political Science Review 98(2):355-370.

Converse, Philip E. 1964. The Nature of Belief Systems in Mass Publics. In Ideology and Discontent, ed. David E. Apter. New York: Free Press pp. 206-261.

Delli Carpini, Michael X. and Scott Keeter. 1996. What Americans Know About Politics and Why It Matters. New Haven, CT: Yale University Press.

DiMaggio, Paul, John Evans and Bethany Bryson. 1996. "Have American's Social Attitudes Become More Polarized?" American Journal of Sociology 102(3):690-755.

Downey, Dennis J. and Matt L. Huffman. 2001. "Attitudinal Polarization and Trimodal Distributions: Measurement Problems and Theoretical Implications." Social Science Quarterly 82(3):494-505.

Ellis, Christopher and James A. Stimson. 2012. Ideology in America. Cambridge: Cambridge University Press.

Erikson, Robert S., Michael B. MacKuen and James A. Stimson. 2002. The Macro Polity. Cambridge: Cambridge University Press.

Evans, John H. 2003. "Have Americans' Attitudes Become More Polarized? - An Update." Social Science Quarterly 84(1):71-90.

Fiorina, Morris P. and Samuel J. Abrams. 2008. "Political Polarization in the American Public." Annual Review of Political Science 11:563-588.

Fiorina, Morris P. and Samuel J. Abrams. 2012. Disconnect: The Breakdown of Representation in American Politics. Norman: University of Oklahoma Press.

Fiorina, Morris P., Samuel J. Abrams and Jeremy C. Pope. 2011. Culture War? The Myth of a Polarized America. 3rd ed. New York: Pearson Longman.

Franklin, Charles H. 1991. "Eschewing Obfuscation? Campaigns and the Perception of U.S. Senate Incumbents." American Political Science Review 85(4):1193-1214. 
Free, Lloyd and Hadley Cantril. 1967. The Political Beliefs of Americans. New York: Free Press.

Geer, John G. and Lynn Vavreck. 2014. "Negativity, Information, and Candidate PositionTaking." Political Communication 31(2):218-236.

Hetherington, Marc J. and Jonathan D. Weiler. 2009. Authoritarianism and Polarization in American Politics. Cambridge: Cambridge University Press.

Hinich, Melvin J. and Michael C. Munger. 1994. Ideology and the Theory of Political Choice. Ann Arbor: University of Michigan Press.

Hinich, Melvin J. and Walker Pollard. 1981. "A New Approach to the Spatial Theory of Electoral Competition." American Journal of Political Science 25(2):323-341.

Hirano, Shigeo, Gabriel S. Lenz, Maksim Pinkovskiy and James M. Snyder. 2014. "Voter Learning in State Primary Elections." Forthcoming, American Journal of Political Science.

Hollibaugh, Gary E., Lawrence S. Rothenberg and Kristin K. Rulison. 2013. "Does It Really Hurt to Be Out of Step?" Political Research Quarterly 66(4):856-867.

Jackman, Simon. 2000. "Estimation and Inference Are Missing Data Problems: Unifying Social Science Statistics via Bayesian Simulation." Political Analysis 8(4):307-332.

Jackman, Simon. 2001. "Multidimensional Analysis of Roll Call Data via Bayesian Simulation: Identification, Estimation, Inference, and Model Checking." Political Analysis $9(3): 227-241$.

Jackman, Simon. 2009. Bayesian Analysis for the Social Sciences. New York: Wiley.

Jacoby, William G. 1995. "The Structure of Ideological Thinking in the American Electorate." American Journal of Political Science 39(2):314-335.

Jacoby, William G. and David A. Armstrong. 2014. "Bootstrap Confidence Regions for Multidimensional Scaling Solutions." American Journal of Political Science 58(1):264278.

Jones, Philip Edward. 2013. "The Effect of Political Competition on Democratic Accountability." Political Behavior 35(3):481-515.

King, Gary, Christopher J.L. Murray, Joshua A. Salomon and Ajay Tandon. 2004. "Enhancing the Validity and Cross-Cultural Comparability of Measurement in Survey Research." American Political Science Review 98(1):191-207.

King, Gary and Jonathan Wand. 2007. "Comparing Incomparable Survey Responses: Evaluating and Selecting Anchoring Vignettes." Political Analysis 15(1):46-66.

Lauderdale, Benjamin E. 2013. "Does Inattention to Political Debate Explain the Polarization Gap between the U.S. Congress and Public?" Public Opinion Quarterly 77(S1):2-23. 
Layman, Geoffrey C. and Thomas M. Carsey. 2002. "Party Polarization and "Conflict Extension" in the American Electorate." American Journal of Political Science 46(4):786-802.

Levendusky, Matthew. 2009. The Partisan Sort: How Liberals Became Democrats and Conservatives Became Republicans. Chicago: University of Chicago Press.

Levendusky, Matthew S. and Jeremy C. Pope. 2011. "Red States vs. Blue States: Going Beyond the Mean." Public Opinion Quarterly 75(2):227-248.

Lewis-Beck, Michael S., William G. Jacoby, Helmut Norpoth and Herbert F. Weisberg. 2008. The American Voter Revisited. Ann Arbor: University of Michigan Press.

Lo, James, Sven-Oliver Proksch and Thomas Gschwend. 2014. "A Common Left-Right Scale for Voters and Parties in Europe." Political Analysis 22(2):205-223.

Mayhew, David R. 1974. Congress: The Electoral Connection. New Haven: Yale University Press.

McCarty, Nolan, Keith T. Poole and Howard Rosenthal. 2006. Polarized America: The Dance of Ideology and Unequal Riches. Cambridge, MA: MIT Press.

Meredith, Mike and Martin Ridout. 2013. overlap: Estimates of Coefficient of Overlapping for Animal Activity Patterns. R package version 0.2.0.

URL: http://CRAN.R-project.org/package=overlap

Miller, Warren E. and Donald E. Stokes. 1963. "Constituency Influence in Congress." American Political Science Review 57(1):45-56.

Nyhan, Brendan, Eric McGhee, John Sides, Seth Masket and Steven Greene. 2012. "One Vote Out of Step? The Effects of Salient Roll Call Votes in the 2010 Election." American Politics Research 40(5):844-879.

Palfrey, Thomas R. and Keith T. Poole. 1987. "The Relationship between Information, Ideology, and Voting Behavior." American Journal of Political Science 31(3):511-530.

Plummer, Martyn. 2003. JAGS: A Program for Analysis of Bayesian Graphical Models Using Gibbs Sampling.

URL: http://mcmc-jags.sourceforge.net/

Plummer, Martyn. 2013. rjags: Bayesian Graphical Models using MCMC. R package version 3-10.

URL: http://CRAN.R-project.org/package=rjags

Poole, Keith, Howard Rosenthal, Jeffrey Lewis, James Lo and Royce Carroll. 2013. basicspace: A Package to Recover a Basic Space from Issue Scales. R package version 0.07.

URL: http://CRAN.R-project.org/package=basicspace

Poole, Keith T. 2005. Spatial Models of Parliamentary Voting. New York: Cambridge University Press. 
Poole, Keith T. and Howard Rosenthal. 1997. Congress: A Political-Economic History of Roll Call Voting. New York: Oxford University Press.

Poole, Keith T. and Howard Rosenthal. 2007. Ideology and Congress. New Brunswick, NJ: Transaction.

Quinn, Kevin M. 2004. "Bayesian Factor Analysis for Mixed Ordinal and Continuous Responses." Political Analysis 12(4):338-353.

Ridout, Martin S. and Matthew Linkie. 2009. "Estimating Overlap of Daily Activity Patterns from Camera Trap Data." Journal of Agricultural, Biological, and Environmental Statistics 14(3):322-337.

Saiegh, Sebastian M. 2009. "Recovering a Basic Space from Elite Surveys: Evidence from Latin America." Legislative Studies Quarterly 34(1):117-145.

Schmid, Friedrich and Axel Schmidt. 2006. "Nonparametric Estimation of the Coefficient of Overlapping-Theory and Empirical Application." Computational Statistics 83 Data Analysis 50(6):1583-1596.

Sherif, Muzafer and Carl I. Hovland. 1961. Social Judgment: Assimilation and Contrast Effects in Communication and Attitude Change. New Haven: Yale University Press.

Shor, Boris and Nolan McCarty. 2011. "The Ideological Mapping of American Legislatures." American Political Science Review 105(3):530-551.

The Cook Political Report. 2010. 2010 Senate Race Rankings (November 1, 2010).

URL: http://cookpolitical.com/charts/senate/raceratings_2010-11-01_12-08-06.php

Treier, Shawn and D. Sunshine Hillygus. 2009. "The Nature of Political Ideology in the Contemporary Electorate." Public Opinion Quarterly 73(4):679-703.

Wand, Jonathan. 2013. "Credible Comparisons Using Interpersonally Incomparable Data: Nonparametric Scales with Anchoring Vignettes." American Journal of Political Science $57(1): 249-262$. 
Table 1: $\alpha$ Values for Selected Republican Respondents

\begin{tabular}{|l|l|l|l|l|}
\hline $\begin{array}{l}\text { ANES } \\
\text { Case ID }\end{array}$ & $\begin{array}{l}\text { Republican } \\
\text { Party Placement }\end{array}$ & $\begin{array}{l}\text { Self } \\
\text { Placement }\end{array}$ & $\begin{array}{l}\alpha \text { Mean } \\
{[95 \% \mathrm{CI}]}\end{array}$ & $\begin{array}{l}\text { Dislike about } \\
\text { Republican Party }\end{array}$ \\
\hline 17 & 4 & 6 & -1.25 \\
{$[-1.89,-0.64]$} & $\begin{array}{l}\text { Don't like the Republican } \\
\text { Party members that claim } \\
\text { to be conservative but } \\
\text { really are not, called [RINOs]. } \\
5479\end{array}$ & 4 & 7 & -1.80 \\
{$[-2.51,-1.15]$} & $\begin{array}{l}\text { They are too liberal; not } \\
\text { conservative enough. }\end{array}$ \\
\hline
\end{tabular}

Table 2: $\alpha$ Values for Selected Democratic Respondents

\begin{tabular}{|l|l|l|l|l|}
\hline $\begin{array}{l}\text { ANES } \\
\text { Case ID }\end{array}$ & $\begin{array}{l}\text { Democratic } \\
\text { Party Placement }\end{array}$ & $\begin{array}{l}\text { Self } \\
\text { Placement }\end{array}$ & $\begin{array}{l}\alpha \text { Mean } \\
{[95 \% \mathrm{CI}]}\end{array}$ & $\begin{array}{l}\text { Dislikes about } \\
\text { Democratic Party }\end{array}$ \\
\hline 5546 & 6 & 2 & $\begin{array}{l}1.98 \\
{[1.20,2.78]}\end{array}$ & $\begin{array}{l}\text { They are just in support of } \\
\text { capitalism and big business as } \\
\text { Republicans and continually alienate } \\
\text { the left and shift to the right } \\
\text { rather than forcing the Republicans } \\
\text { to move left and speak honestly } \\
\text { about their policies. }\end{array}$ \\
5602 & 5 & 3 & $\begin{array}{l}1.99 \\
{[1.48,2.52]}\end{array}$ & $\begin{array}{l}\text { They won't stand up to big pharma } \\
\text { companies, or big banks, or giant } \\
\text { corporations like I wish they would. }\end{array}$ \\
\hline
\end{tabular}


Table 3: Respondent Ideological Position and Mean $\alpha$ Values in the 2010 Cooperative Congressional Election Study

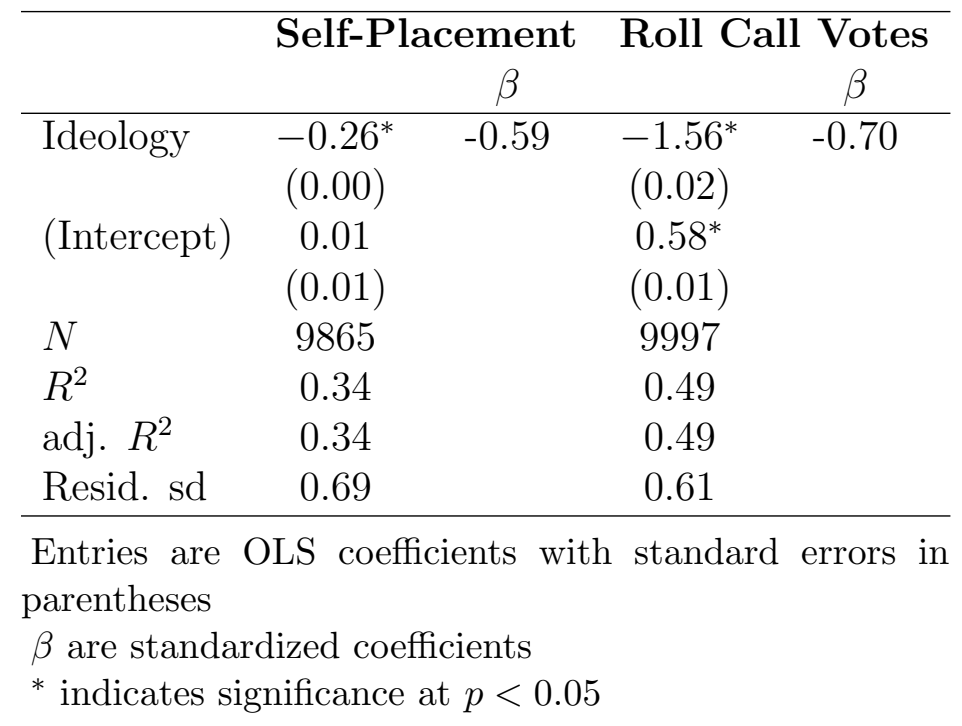

Table 4: Determinants of Perceived Ideological Positions of Senators and Senatorial Candidates in 2010

\begin{tabular}{lcc|cc|cc}
\hline & \multicolumn{2}{c|}{ All } & \multicolumn{2}{c|}{ Democrats } & \multicolumn{2}{c}{ Republicans } \\
& & $\beta$ & & $\beta$ & \multicolumn{2}{c}{$\beta$} \\
\hline DW-NOMINATE Score & $1.11^{*}$ & 0.56 & $1.36^{*}$ & 0.68 & $0.65^{*}$ & 0.57 \\
& $(0.13)$ & & $(0.20)$ & & $(0.15)$ & \\
CF Score & $0.37^{*}$ & 0.43 & 0.09 & 0.13 & 0.19 & 0.21 \\
& $(0.06)$ & & $(0.07)$ & & $(0.13)$ & \\
(Intercept) & -0.02 & & $-0.22^{*}$ & & $0.39^{*}$ & \\
& $(0.02)$ & & $(0.06)$ & & $(0.09)$ & \\
$N$ & 105 & & 59 & & 46 & \\
$R^{2}$ & 0.95 & & 0.57 & & 0.51 & \\
adj. $R^{2}$ & 0.95 & & 0.56 & & 0.48 & \\
Resid. sd & 0.17 & & 0.14 & & 0.15 & \\
\hline
\end{tabular}

Entries are OLS coefficients with standard errors in parentheses

$\beta$ are standardized coefficients

* indicates significance at $p<0.05$ 
Figure 1: Mean $\alpha$ Values across Partisan and Ideological Groups in the 2012 American National Election Study

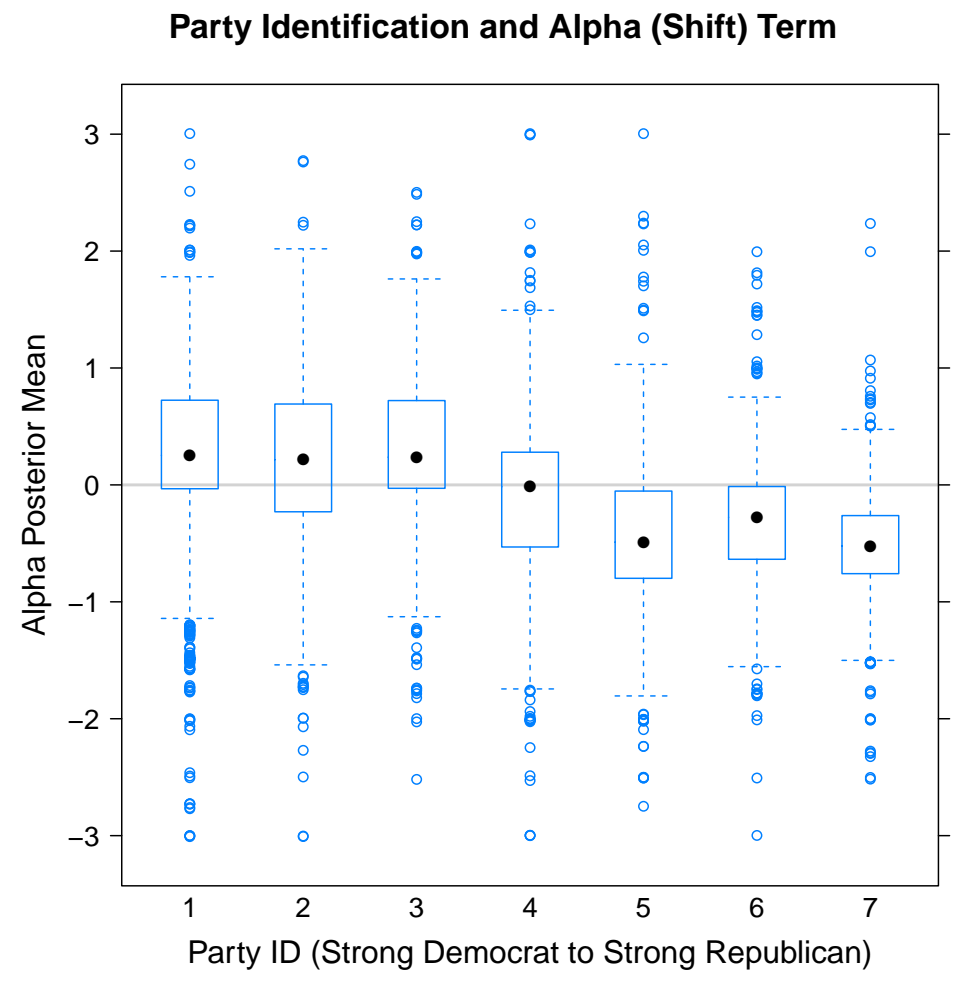

\section{Ideological Self-Placement and Alpha (Shift) Term}

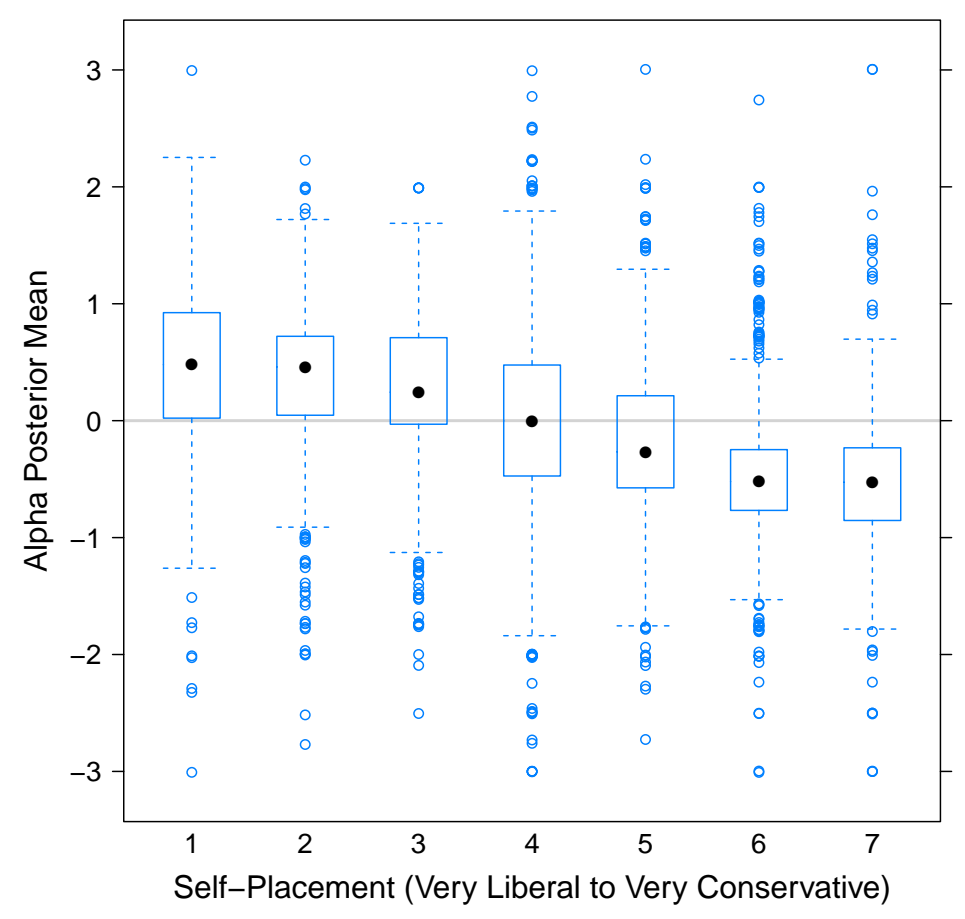


Figure 2: Ideological Distribution of 2012 American National Election Study Respondents
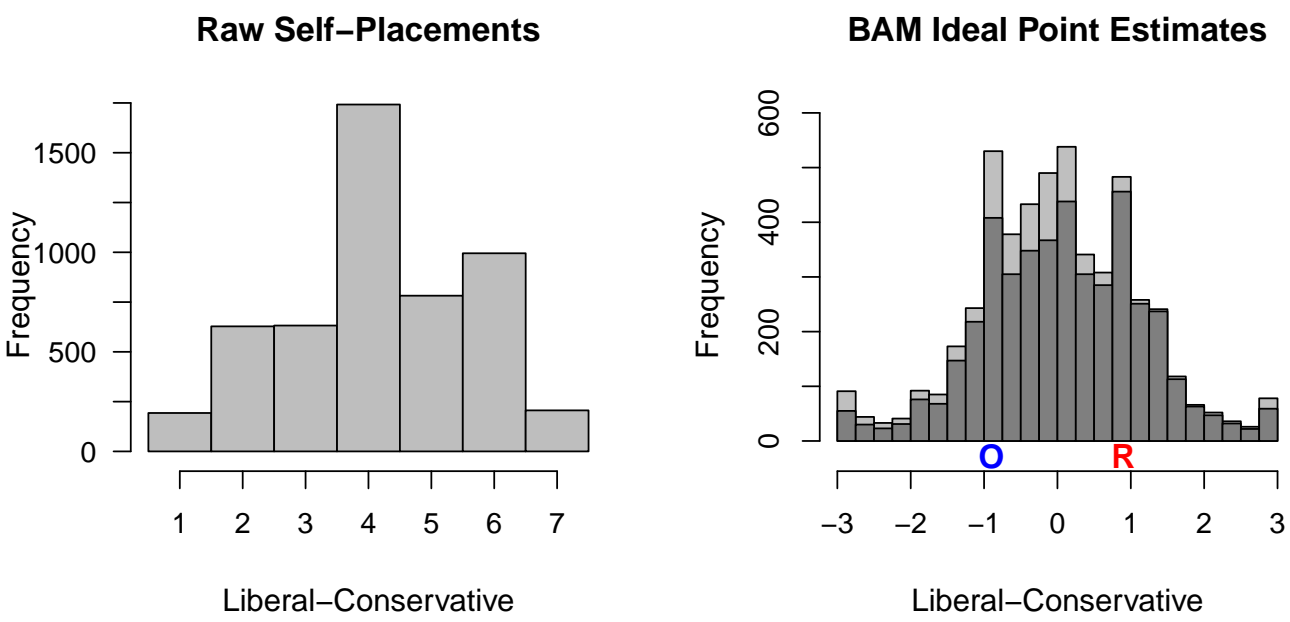

Notes: The dark gray bins isolate the estimated ideal points of respondents with positive $\beta$ values. "O" and "R" denote the estimated positions of Obama and Romney. 
Figure 3: Overlap of Selected Groups on the Liberal-Conservative Dimension

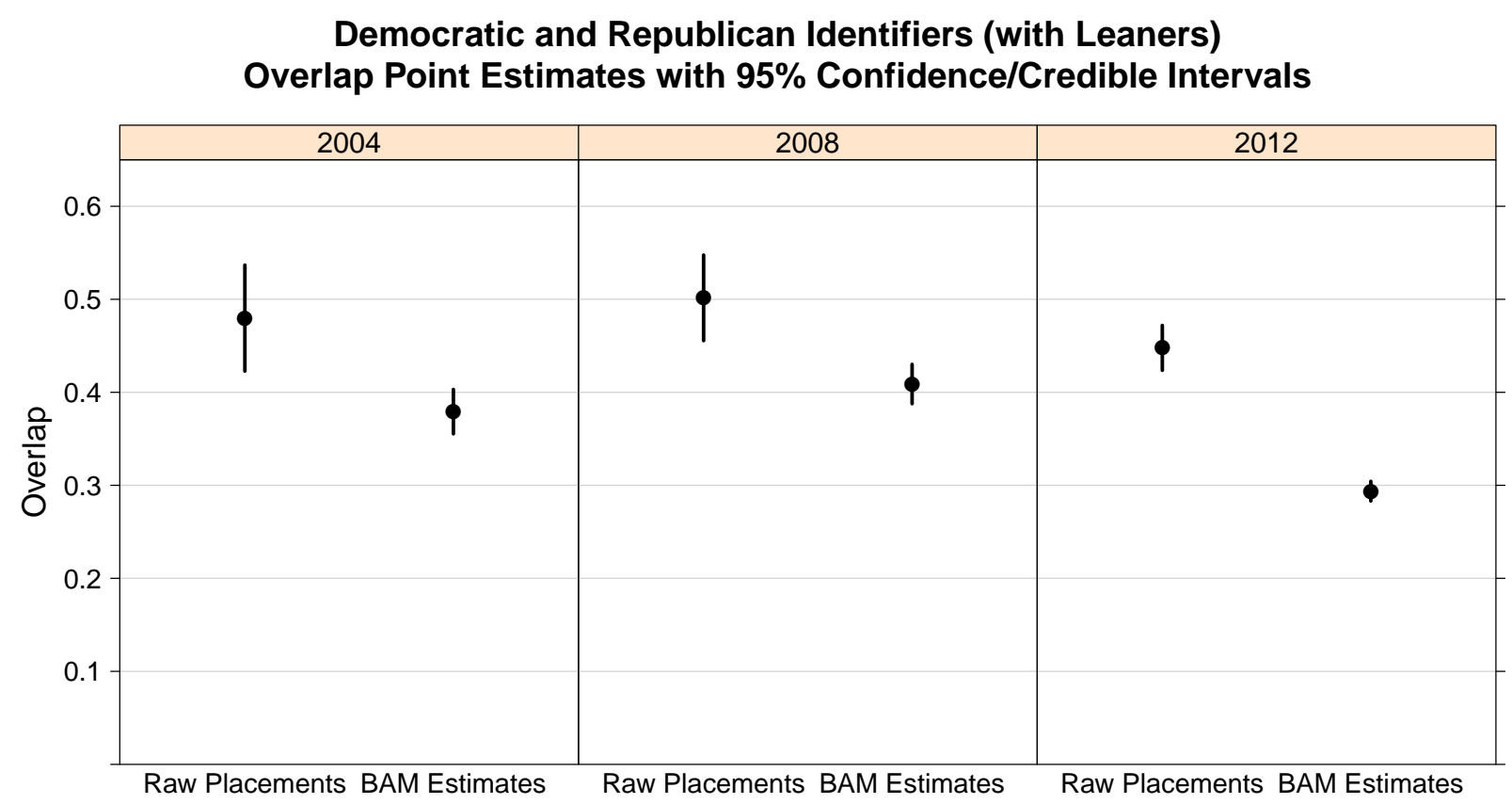

Democratic and Republican Presidential Vote Choice Overlap Point Estimates with $95 \%$ Confidence/Credible Intervals

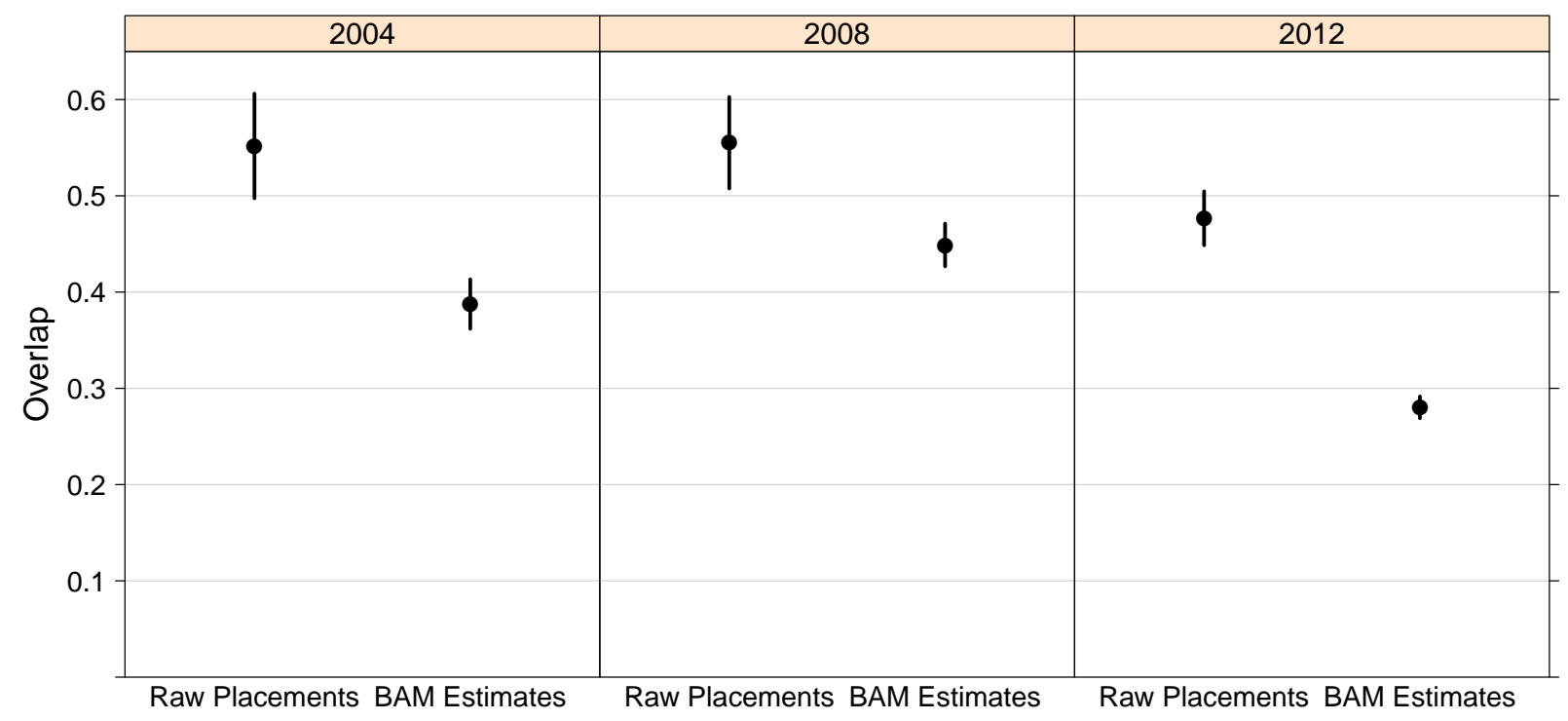


Figure 4: Mean Obama Liberal-Conservative Placement (Top Panel) and Mean Alpha Values (Bottom Panel) by State
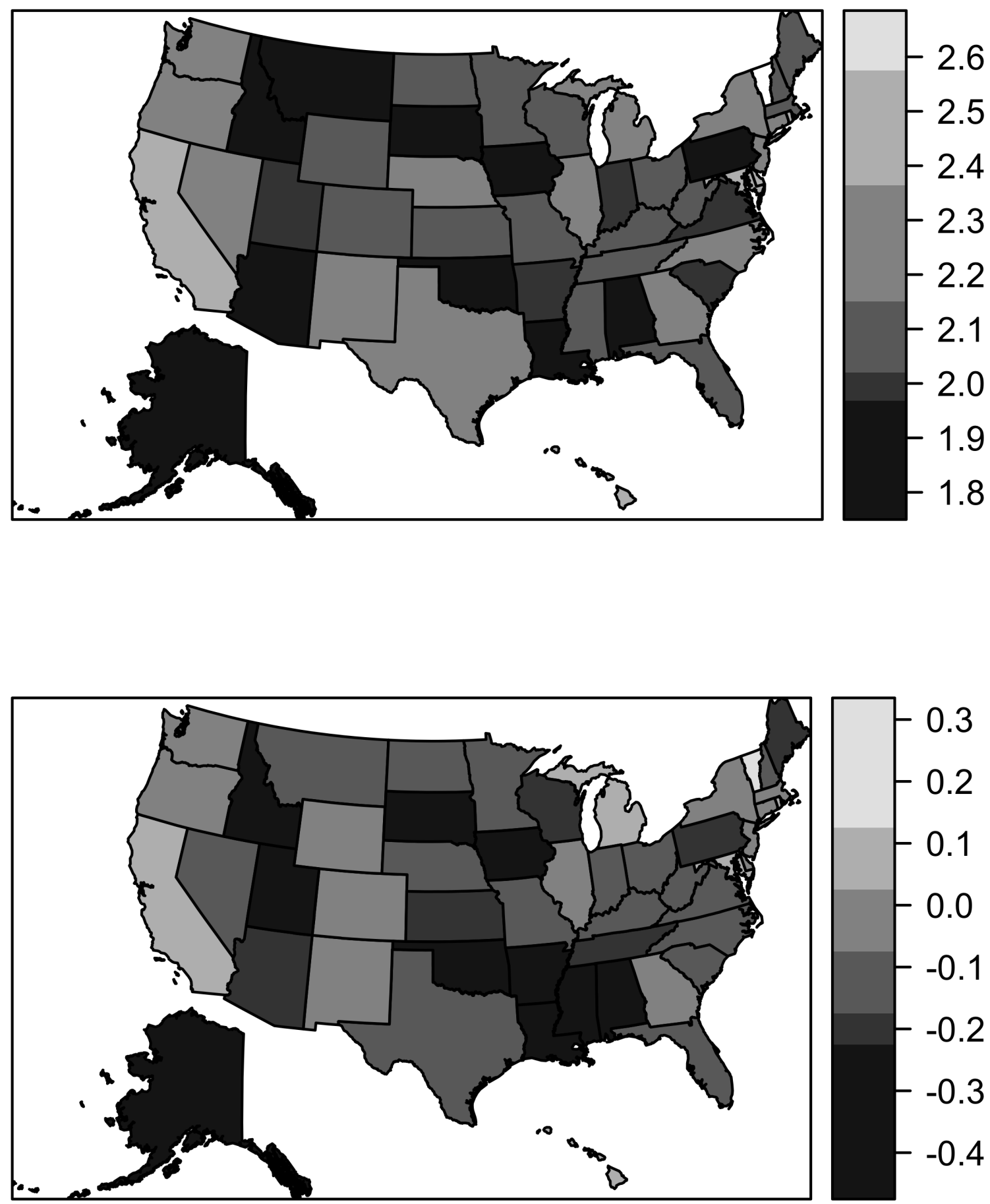
Figure 5: Comparison of Ideological Estimates of Senators and Senatorial Candidates in 2010

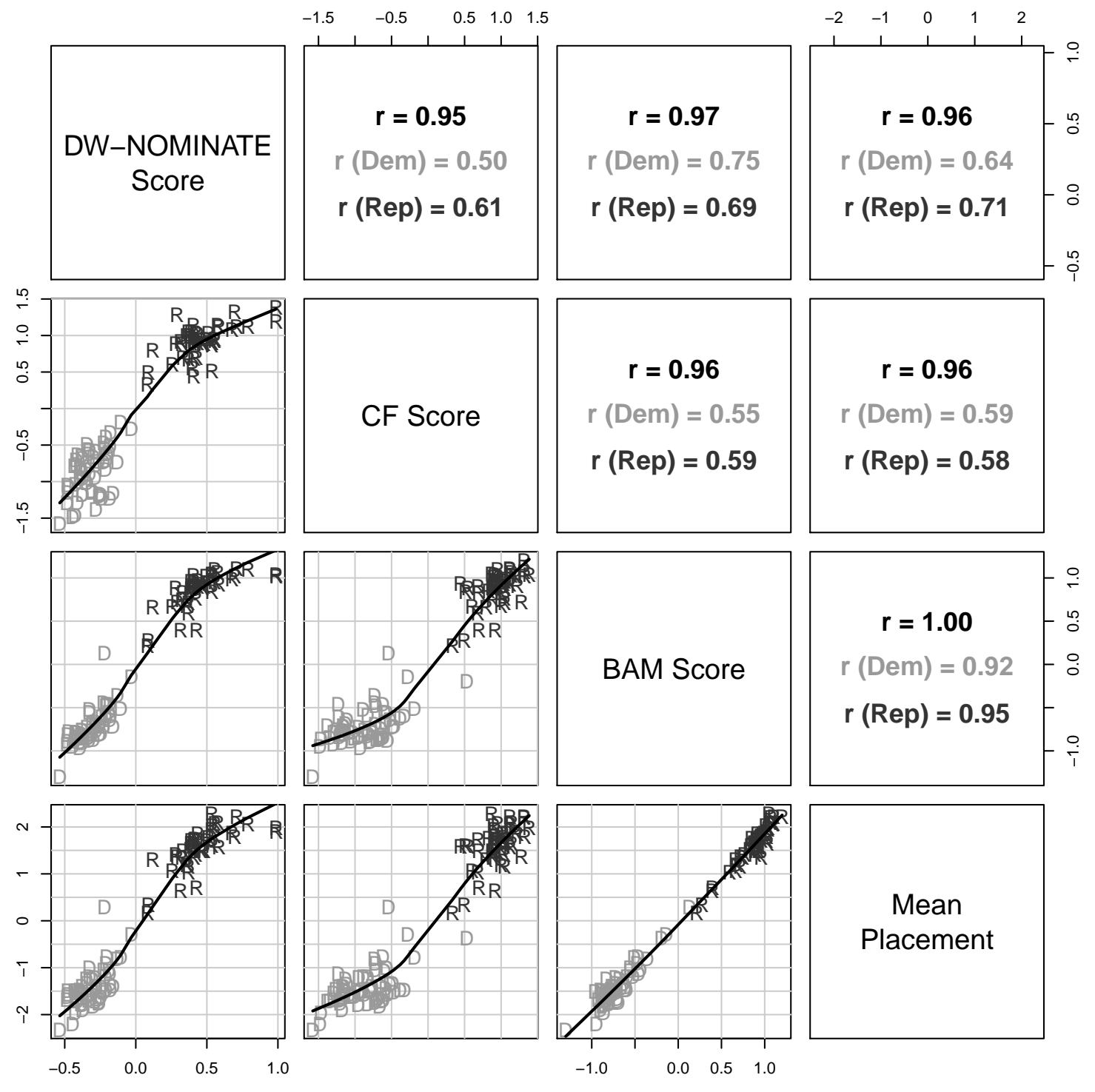

